Revista Destaques Acadêmicos, Lajeado, v. 12, n. 2, 2020. ISSN 2176-3070

DOI: http://dx.doi.org/10.22410/issn.2176-3070.v12i2a2020.2499

http://www.univates.br/revistas

\title{
METODOLOGIAS ATIVAS NOS CURSOS TÉCNICOS DE ADMINISTRAÇÃO: REVISÃO INTEGRATIVA
}

\author{
Luana De Maman ${ }^{1}$, Maria Claudete Schorr ${ }^{2}$
}

Resumo: O uso das Metodologias Ativas está cada vez mais presente no ensino, tendo em vista a formação de um estudante ativo e protagonista de seu processo de aprendizagem. Diante disso, este artigo apresenta uma revisão integrativa sobre a utilização das Metodologias Ativas nos cursos Técnicos de Administração sob a concepção da literatura científica. Para a revisão integrativa utilizou-se a base de dados do portal de periódicos da Universidade do Vale do Taquari (Univates) e a base de dados da Scientific Electronic Library Online (Scielo). Para seleção dos estudos, os critérios de inclusão utilizados foram os artigos que apresentaram na íntegra abordagem das técnicas de metodologias ativas na área de educação profissional, selecionando-se para análise do conteúdo sete artigos. Entre os principais resultados encontrados ressalta-se a postura ativa e crítica que os estudantes adotam por meio das metodologias ativas aplicadas, além de desenvolver a autonomia, criatividade, tomada de decisão, troca de experiências e participação ativa. A partir deste resultado conclui-se a importância da inclusão das metodologias ativas nas práticas pedagógicas por parte dos docentes, favorecendo a formação de profissionais técnicos qualificados e bem preparados para o mercado de trabalho.

Palavras-chave: Metodologias ativas. Ensino Técnico. Técnico de Administração.

\section{INTRODUÇÃO}

Os diferentes contextos educacionais no Brasil percorrem caminhos desde escolas em que estudantes passam o dia copiando textos, até instituições que possibilitam os recursos mais modernos em tecnologia, tanto para os

1 Graduada/Bacharela em Ciências Contábeis. Acadêmica do Curso de Pós-Graduação Lato Sensu - Especialização em Docência na Educação Profissional da Univates.

2 Possui Licenciatura em Computação pela Universidade de Santa Cruz do Sul - UNISC (2003), especialização em Tecnologias em Educação pela PUC - Rio (2010) e Mestrado em Ensino de Ciências Exatas pelo Centro Universitário UNIVATES (2015). Atualmente é professora da Univates e do Colégio Cenecista João Batista de Mello - CNEC Lajeado. Desde 2004 coordena os projetos de Informática e Robótica do Colégio Cenecista João Batista de Mello. Tem experiência em Informática, com ênfase em Tecnologias na Educação. 
professores como para os alunos. A tecnologia integra todos os espaços e tempos. Moran (2015) já mencionava que o ensinar e aprender estão interligados entre o espaço físico e digital, sendo essencial para realizar a conexão entre o mundo e a escola.

A educação se constitui como um dos pilares mais importantes para a formação de uma sociedade mais justa e defensora da cidadania. Segundo Ribeiro (2018), para superar formas inerentes e conservadoras no meio educacional, torna-se necessário incluir ações inovadoras que as tecnologias da informação e comunicação podem proporcionar, possibilitando à facilitação e desenvolvimento do processo de ensino e aprendizagem e a construção de conhecimento, competências e saberes.

Porém, para que as necessidades do mundo contemporâneo sejam atendidas, e os estudantes da educação profissional sejam capazes de satisfazer a estas demandas, as escolas tradicionais devem abrir espaço para a aprendizagem estruturada em aspectos como solução de problemas, criatividade, inovação, capacitação e visão empreendedora (BARBOSA; MOURA, 2013).

Neste sentido, as Diretrizes Curriculares Nacionais Para a Educação Profissional Técnica de Nível Médio do Brasil (BRASIL, 2012), estabelecem que os Cursos de Educação Profissional Técnica de Nível Médio devem possuir como principal finalidade proporcionar aos estudantes conhecimento, saberes e competências profissionais, essenciais para o exercício profissional e a cidadania. Da mesma forma, segundo Berbel (2011), as metodologias ativas fundamentam-se em formas de desenvolver o processo de aprender, aplicando experiências reais ou simuladas, objetivando as condições de solucionar, com êxito, desafios resultantes das atividades essenciais da prática social, em diferentes contextos.

As metodologias ativas de aprendizagem se configuram como alternativas para uma aprendizagem eficiente que possibilita ao aluno ser o protagonista e o professor assumir o papel de orientador. A prática na Educação Profissional compreende diferentes situações de vivência, aprendizagem e trabalho como experimentos e atividades em ambientes especiais, possibilitando aos estudantes vivenciarem situações reais de trabalho.

Para que isso aconteça, não basta colocar o aluno na frente de um computador ou celular e propor uma pesquisa na internet. Segundo Barbosa e Moura (2013), os Cursos Técnicos devem possibilitar a formação não somente de indivíduos tecnicamente bem preparados, mas também que sejam capazes de exercer valores e condições de formação humana, indispensáveis no mundo de trabalho contemporâneo, tais como conduta ética, capacidade de iniciativa, criatividade, flexibilidade, autocontrole e comunicação. Nesse contexto, o presente trabalho tem como objetivo principal identificar como estão sendo desenvolvidas as metodologias ativas nos Cursos Técnicos de Administração sob a concepção da literatura científica. 
Justifica-se o presente trabalho pela necessidade de identificar se o uso das metodologias ativas está sendo inserida como ferramenta pedagógica na formação profissional do Técnico de Administração e como tem produzido resultados em relação ao processo de Ensino e Aprendizagem.

\section{PROCEDIMENTOS METODOLÓGICOS}

A revisão integrativa é uma abordagem referente às revisões, permitindo a inclusão de estudos experimentais e não experimentais para um melhor entendimento do fenômeno analisado. Integra diversos propósitos como definição de conceitos, revisão de teorias, evidências e análise de problemas metodológicos de determinado assunto (SOUZA et al., 2010).

Para a revisão integrativa proposta no presente trabalho, utilizou-se a base de dados do Portal de Periódicos da Universidade do Vale do Taquari (Univates) e a base de dados Scientific Electronic Library Online (Scielo). A busca pelos artigos foi realizada utilizando-se as palavras chaves "Metodologias Ativas" AND "Educação Profissional" AND "Administração".

Neste sentido, realizou-se uma revisão integrativa dos trabalhos de pesquisa realizados acerca do uso de metodologias ativas especificamente no universo do Ensino Profissional do Curso de Administração, delimitando-se o período da busca aos últimos 10 (dez) anos, entre 2010 e 2019, e selecionando a busca pelo idioma português. A coleta de dados ocorreu no ano de 2019. Primeiramente foram encontrados 95 estudos na base de dados da Univates e 1 estudo na base de dados da Scielo.

Para seleção dos estudos, os critérios de inclusão foram os artigos que apresentaram na íntegra abordagem das técnicas de metodologias ativas na área de educação profissional, com disponibilidade online e gratuitos, excluindo-se os estudos repetidos. Para o acesso aos textos foi utilizado o link disponível na própria base de dados selecionada. Para seleção dos artigos, foi realizada a análise dos títulos dos estudos partindo do protocolo de revisão conforme Figura 1. 
Figura 1 - Protocolo de análise dos estudos

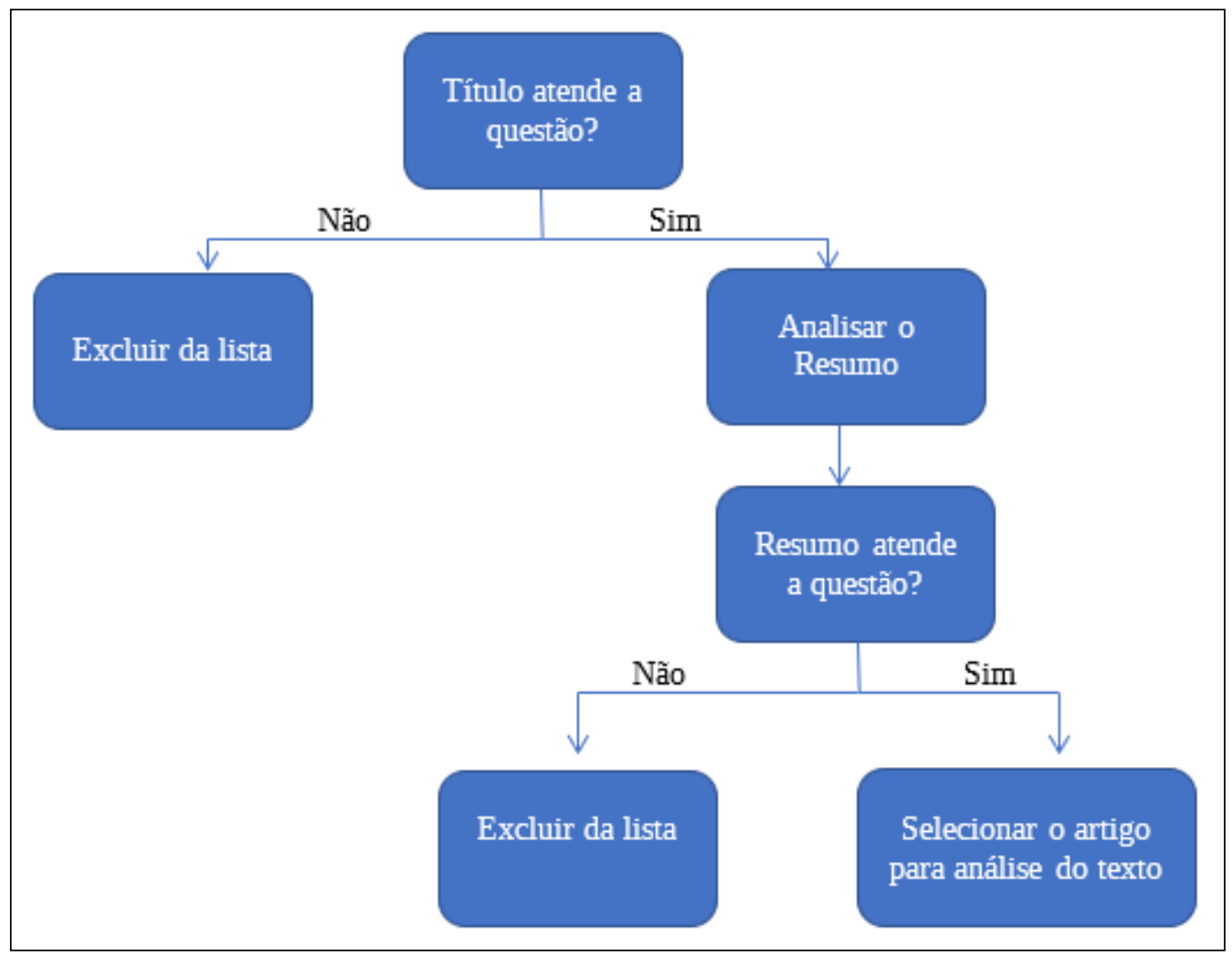

Fonte: Dos autores, 2020.

Com base na definição dos critérios de inclusão e exclusão, a revisão integrativa deste estudo integrou-se de sete artigos selecionados para análise dos resultados. Todos os artigos selecionados tiveram delineamento qualitativo.

O primeiro estágio da análise do material foi efetuar a leitura e construção do quadro sintético (Quadro 1). Para construção do quadro foram extraídas as seguintes informações dos artigos: base de dados, autor (es), título, periódico, ano de publicação e procedência do estudo. Posteriormente, na fase de interpretação dos resultados, foram observados os encontros e conflitos presentes na concepção dos diferentes autores. Os elementos éticos como autoria e citações dos autores foram preservados e respeitados.

\section{RESULTADOS E DISCUSSÕES}

As publicações científicas identificadas que abordam o tema das metodologias ativas de aprendizagem nos cursos técnicos de Administração são apresentadas no Quadro 1. 
Quadro 1 - Fontes bibliográficas que englobam a revisão integrativa, segundo a base de dados consultada, autor (es), título, ano de publicação e procedência do estudo.

\begin{tabular}{|c|c|c|c|c|c|}
\hline $\mathrm{N}^{\circ}$ & $\begin{array}{l}\text { Base de } \\
\text { dados }\end{array}$ & Autor (es) & Título & Ano & $\begin{array}{c}\text { Procedência do } \\
\text { estudo }\end{array}$ \\
\hline I & UNIVATES & $\begin{array}{l}\text { André Luis } \\
\text { Eifler }\end{array}$ & $\begin{array}{c}\text { Avaliação do desenvolvimento } \\
\text { da metodologia de aprendizagem } \\
\text { baseada em problemas na disciplina } \\
\text { de contabilidade no curso técnico em } \\
\text { administração }\end{array}$ & 2019 & UNIVATES \\
\hline II & UNIVATES & $\begin{array}{l}\text { Carlos Menta } \\
\text { Giasson }\end{array}$ & $\begin{array}{c}\text { Metodologias ativas no ensino de } \\
\text { matemática financeira em nível } \\
\text { técnico profissionalizante: percepção } \\
\text { de estudantes } \\
\end{array}$ & 2018 & UNIVATES \\
\hline III & UNIVATES & $\begin{array}{l}\text { Jorge Lauri } \\
\text { Mörschbächer }\end{array}$ & $\begin{array}{l}\text { Contribuições e desafios da } \\
\text { metodologia instrução entre pares: um } \\
\text { estudo de caso no ensino técnico }\end{array}$ & 2018 & UNIVATES \\
\hline IV & UNIVATES & Luciana Brune & $\begin{array}{c}\text { Impactos da estratégia World Café } \\
\text { num curso técnico em administração: } \\
\text { motivação, participação e aprendizado } \\
\text { em sala de aula }\end{array}$ & 2018 & UNIVATES \\
\hline $\mathrm{V}$ & SCIELO & $\begin{array}{l}\text { Taís Fim } \\
\text { Alberti et al. }\end{array}$ & $\begin{array}{c}\text { Dinâmicas de grupos orientadas } \\
\text { pelas atividades de estudo: } \\
\text { desenvolvimento de habilidades } \\
\text { e competências na educação } \\
\text { profissional }\end{array}$ & 2014 & UFSM \\
\hline VI & UNIVATES & $\begin{array}{c}\text { Dewey } \\
\text { Wollmann }\end{array}$ & $\begin{array}{c}\text { Analytic Hierachy Process suportando } \\
\text { a avaliação por pares }\end{array}$ & 2017 & PUCPR \\
\hline VII & UNIVATES & $\begin{array}{c}\text { Fausto } \\
\text { Camargo et al. }\end{array}$ & $\begin{array}{c}\text { O Uso do Team-Based Learning como } \\
\text { Estratégia de Avaliação Formativa } \\
\text { no Curso de Administração da } \\
\text { Uniamérica }\end{array}$ & 2017 & UNIAMÉRICA \\
\hline
\end{tabular}

Fonte: Dos autores, 2020.

Todos os artigos tratam de metodologias ativas de aprendizagem sendo que cinco foram desenvolvidos no estado do Rio Grande do Sul e dois no Paraná. Conforme o Quadro 1, em relação ao ano de publicação um artigo foi publicado no ano de 2019, três em 2018, dois em 2017 e um em 2014.

A educação profissional possibilita diversas oportunidades de aplicação de metodologias ativas de aprendizagem em diferentes contextos de formação profissional. É o caso das dinâmicas em grupo, oficinas, trabalho em equipe, desenvolvimento de projetos, visitas técnicas, discussões em grupos, jogos, simulações. Conforme Barbosa e Moura (2013, p. 56) “Essas atividades tendem a ser naturalmente participativas e promovem o envolvimento do aluno no processo de aprendizagem". O mesmo autor enfatiza:

Entretanto, se de um lado vivenciamos com mais facilidade os métodos ativos de aprendizagem nas atividades práticas, por outro 
lado, resta-nos enfrentar um dos grandes desafios pedagógicos dos tempos modernos: incorporar aprendizagem ativa nos espaços e tempos atualmente ocupados pelas tradicionais aulas expositivas. É exatamente ali, na sala de aula e nas relações entre professor e aluno, onde as mudanças são mais necessárias. (BARBOSA; MOURA, 2013. p. 56)

$\mathrm{O}$ artigo I destaca que ao aplicar as metodologias ativas, o papel do professor passa a ser de facilitador na construção do conhecimento e para isso, precisa tornar o ambiente de ensino e aprendizagem mais dinâmico e instigar a cooperação entre pares na sala de aula. Para isso foi proposta a aplicação da metodologia da Aprendizagem Baseada em Problemas, conhecida pela sigla ABP. Este método de ensino segundo Barbosa e Moura (2013), fundamentase no uso contextualizado de uma situação problema para o aprendizado autodirigido e o ponto central do aprendizado é o aluno.

A ABP transforma um problema como base de motivação para $o$ aprendizado. $\mathrm{O}$ contexto não é ter sempre o problema resolvido no final do trabalho, mas sim ressaltar o processo seguido pelo grupo na busca de uma solução, com ênfase na aprendizagem autônoma e cooperativa (BARBOSA; MOURA, 2013).

Ao encontro do artigo I, o artigo II procurou identificar a percepção dos estudantes quanto à aplicação das metodologias ativas de aprendizagem pelos docentes e se os resultados obtidos eram melhores do que quando aplicado as metodologias tradicionais de aprendizagem. A metodologia ativa escolhida foi a mesma do artigo I, a ABP. Para constatação dos resultados foram aplicadas técnicas tradicionais e técnicas de ABP em uma turma de estudantes. Foi realizada comparação dos resultados e percepção do aprendizado pelos discentes e docentes.

No ensino tradicional, baseado na transmissão do conteúdo, os alunos possuem postura passiva diante do processo de ensino e aprendizagem. Poucos são os momentos em que podem se manifestar e se posicionar de forma crítica. Por meio das técnicas de metodologias ativas, o aluno passa a ser o principal responsável pelo aprendizado, desenvolvendo postura crítica e autonomia que inspiram a análise de fatos e tomada de decisão (DIESEL; MARCHEZAN; MARTINS, 2016).

De acordo com os questionários respondidos pelos estudantes alvo da pesquisa do artigo II, ficou evidenciado que a maioria dos estudantes preferem intercalar aulas do modelo tradicional com aulas de metodologia diferenciada. Quanto à metodologia escolhida a resposta da maioria foi que o conhecimento adquirido com a aplicação da atividade de ABP foi melhor, facilitando o aprendizado em comparação às demais. Segundo Berbel (2011), aprender por meio da ABP relacionada com a sua área, vem se tornando uma oportunidade de envolvimento ativo dos alunos em seu próprio desenvolvimento de formação. 
O artigo III refere-se ao estudo e aplicação da metodologia ativa Instrução entre Pares, também conhecida por Peer Instruction. A pesquisa tem por finalidade analisar se esta metodologia traz resultados eficazes nos processos de ensino e aprendizagem.

De acordo com GODOI (2016), essa metodologia foi criada por Eric Mazur professor da Harvard University e destaca-se pela aplicabilidade dos conceitos através da discussão entre os alunos. É uma técnica de ensino criada para auxiliar a tornar as aulas mais interativas e interessantes e fornecer ao professor um feedback sobre o estágio de aprendizagem da turma.

A técnica aplicada na pesquisa consiste em estudar o conteúdo por meio do material indicado pelo professor antes do início da aula. Em sala de aula, depois da exposição do professor, ele formula perguntas e aplica de forma individual ao aluno que deve refletir e elaborar justificativas para a resposta. Posteriormente, os alunos devem debater e discutir entre si, tentando convencer seus pares do porque sua resposta seria correta até chegar a um consenso. A partir de então, o professor aborda a questão e suas diferentes respostas, abrindo espaço para a discussão e esclarecimentos necessários.

Conforme Godoi (2016), o entendimento e domínio conceitual é o primeiro passo para adquirir conhecimento em uma área em específico, para posteriormente desenvolver suas habilidades para que possam aplicá-los em situações práticas, como é o esperado dos profissionais em suas áreas de atuação, em especial a área de Administração.

Entre os resultados encontrados na aplicação do método do artigo III, o autor destaca a percepção de uma interação positiva entre aluno e professor. A aula tornou-se dinâmica com a participação efetiva dos alunos e interação entre colegas, principalmente pela cooperação na busca pelo conhecimento e o aumento da criticidade dos alunos com relação ao aprendido e ao que é aplicável na vida real.

A proposta do artigo IV analisou os impactos da aplicação da metodologia ativa World Café, avaliando a motivação, interesse e participação dos alunos e os possíveis aprendizados decorrentes desta metodologia.

A técnica World Café baseia-se no trabalho em equipe. Os alunos são reunidos em grupo e devem chegar a um consenso sobre uma sugestão para resolver o problema que o professor indicou. Após, os integrantes trocam de ilha e passam a focar na solução do problema seguinte, e assim sucessivamente. Os líderes, que ficam fixos em uma determinada ilha, interagem com toda a turma. Ao final, cada grupo diante do problema inicial, que agora está enriquecido com novas ideias, passa a focar na melhor solução dentre as apresentadas e devem tomar a decisão de qual ideia será apresentada para a direção da suposta empresa (FERNANDES, 2015).

A metodologia ativa apresentada no estudo IV vai ao encontro de que Morán (2015, pg. 19), destaca, "Nas metodologias ativas de aprendizagem, o 
aprendizado se dá a partir de problemas e situações reais; os mesmos que os alunos vivenciarão depois na vida profissional, de forma antecipada, durante o curso".

O estudo do artigo IV demonstrou através dos resultados encontrados que foi possível identificar um crescente impulso para a criatividade, troca de experiência, participação e aprendizagem coletiva, com foco na aula prática simulando situações reais de gestão administrativa, que os alunos enfrentarão no ambiente de trabalho.

$\mathrm{O}$ artigo $\mathrm{V}$ procurou estudar sobre as dinâmicas de grupo na sala de aula e sua influência para aquisição de conhecimento teórico-práticos e no desenvolvimento de competências e habilidades na formação do Técnico em Administração de Empresas. Foram desenvolvidas dinâmicas de equipes com o objetivo de problematizar conceitos que envolvem motivação, criatividade, liderança, comunicação entre outros. As atividades tinham como foco principal conduzir os sujeitos ao alcance de novas formações em seu desenvolvimento e, ainda, à mobilização do que aprenderam na realização de novas tarefas.

Com a utilização das dinâmicas em grupo aplicadas, o estudo do artigo $\mathrm{V}$ procurou analisar se os estudantes tornaram-se mais capacitados para o domínio do trabalho, não apenas no conhecimento teórico, mas também na capacidade de intervir tanto em situações conhecidas quanto nas não esperadas, que exigem criatividade e rapidez. As atividades que vinculam teoria com a prática podem aperfeiçoar o conteúdo e os métodos de ensino e formação, influenciando qualitativamente no desenvolvimento intelectual dos indivíduos.

Conforme os Princípios da Educação Profissional Técnica de Nível Médio, a escolarização profissional e tecnológica é um componente primordial da atividade humana orientada para o desenvolvimento integral do sujeito e na preparação para o exercício das profissões técnicas, possuindo como um dos norteadores a associação entre teoria e prática no processo de ensinoaprendizagem (BRASIL, 2012).

$\mathrm{O}$ artigo VI destaca que os profissionais da Administração devem possuir habilidades técnicas, humanas e conceituais, e para que essa multidimensionalidade possa ser desenvolvida pelos gestores da área, metodologias ativas devem ser utilizadas. $\mathrm{O}$ autor do artigo afirma que os métodos participativos são capazes de desafiar o aluno a argumentar e pensar contribuindo para uma aprendizagem ativa. O objetivo do trabalho foi analisar o uso da técnica de análise multicritério denominada Analytic Hierarchy Process (AHP), com o propósito de desenvolver as habilidades humanas dos estudantes dos cursos de Administração.

Segundo Barin et al. (2010), a mente humana distribui elementos em grupos de acordo com propriedades, estruturando o raciocínio e a consequente tomada de decisão. Fundamenta-se em análise de julgamento entre pares de 
alternativas, sob a óptica de diversos critérios de avaliação. Assim, o professor pode estabelecer seus critérios de avaliação dos grupos, hierarquizá-los e comunicá-los aos estudantes. Os estudantes de cada equipe observam seus colegas e os julgam, comparando os desempenhos dois a dois.

Conforme analisado no artigo VI, a autoavaliação e a avaliação por pares podem trazer benefícios relevantes para todos os envolvidos no processo de aprendizagem. Ao aprender avaliar seu trabalho e dos colegas, fortalece a capacidade de julgamento, melhoram seus desempenhos e desenvolvem hábitos de colaboração. Além disso, levam para a vida profissional essa capacidade de se avaliar como membro de equipes, avaliar grupos de trabalho e considerar pontos de melhoria.

$\mathrm{O}$ artigo VII buscou analisar a metodologia ativa conhecida como Aprendizagem Baseada em Equipes (Team-based Learning, TBL). O estudo pretendeu analisar o desempenho dos alunos e os possíveis ganhos na aprendizagem quando aplicado a técnica TBL.

De acordo com Watté et al. (2018), o TBL consiste em uma forma de aprendizagem prática que o estudante interage com os demais colegas. É uma estratégia que exige do professor menos exposição teórica e mais acompanhamento sobre o que os alunos estão desenvolvendo em aula. No primeiro momento o professor aplica um teste individual para verificar o domínio de cada aluno. Em seguida, os alunos se reúnem em grupos para realizar o mesmo teste e responder às mesmas questões. Nesse momento ocorre a primeira interação entre o grupo, onde os alunos expõem seus argumentos com o intuito de chegarem a um consenso na resposta de cada pergunta. O papel do professor é acompanhar o desenvolvimento das ideias e dos debates.

Para Watté et al. (2018, p. 112) “ Incluir uma estratégia TBL em disciplinas que possuem impacto direto no desenvolvimento econômico e social é um desafio que tende a gerar grandes contribuições no ambiente acadêmico e profissional".

Ao aplicar a proposta do artigo VII, os resultados puderam inferir que as argumentações, discussões e debates, consequentes das atividades em grupo contribuem significativamente com o processo de ensino e aprendizagem, pois auxiliam o estudante em seu desenvolvimento acadêmico e profissional através da participação ativa.

Portanto, diante dos estudos selecionados na revisão integrativa, podese destacar a importância das metodologias ativas no processo de Ensino e Aprendizagem dos cursos Técnicos em Administração. Nesta área é muito importante que os alunos adquiram experiências práticas e simulações reais que posteriormente viverão em seus ambientes de trabalho, gerando desta forma profissionais mais capacitados ao trabalho. 


\section{CONSIDERAÇÕES FINAIS}

As metodologias ativas se configuram como uma promessa de revolução no ensino, pois proporcionam aos alunos uma aprendizagem dinâmica e aulas que despertam maior interesse e participação, tornando os alunos protagonistas do próprio conhecimento (WATTÉ, 2018).

Levando-se em consideração a relevância da prática no processo de ensino e aprendizagem, percebe-se a importância das metodologias ativas na formação do profissional técnico em administração, possibilitando aos estudantes vivenciarem experiências e situações comuns no ambiente de trabalho e de gestão empresarial.

Entre os principais resultados encontrados destaca-se a postura ativa que os estudantes adotam com as metodologias aplicadas, além de desenvolver autonomia e olhar crítico. As características desenvolvidas pelos alunos a partir das práticas pesquisada nos artigos são a capacidade para tomada de decisões, criatividade, troca de experiências e participação ativa. Estas capacidades são fundamentais na formação técnica e reflete em um futuro profissional competente e bem preparado para o mercado de trabalho.

Todavia, através das pesquisas realizadas, pode-se ressaltar a importância da mudança pedagógica por parte dos docentes do ensino profissional, através da inclusão das metodologias ativas nas suas práticas pedagógicas, visando colaborar com o processo de ensino e aprendizagem dos estudantes, favorecendo a formação de profissionais técnicos qualificados. Sendo assim, o aluno também se torna responsável pela sua formação, desenvolvendo raciocínio crítico, social e ético, além de estar se preparando para buscar soluções para os problemas administrativos relacionados com a área dentro da empresa.

Especificamente em relação ao ensino Profissional, verificou-se que há poucas pesquisas relacionadas às metodologias ativas desenvolvidas nos cursos técnicos em administração, o que se estabelece uma limitação ao presente trabalho. Porém, percebendo o Ensino Técnico como um espaço em pleno crescimento, há imensas possibilidades de novas pesquisas e futuras investigações.

\section{REFERÊNCIAS}

ALBERTI, Taís Fim; ABEGG, Ilse; COSTA, Marcia Rejane Julio; TITTON, Mauro. Dinâmicas de grupos orientadas pelas atividades de estudo: desenvolvimento de habilidades e competências na educação profissional, 2014. Disponível em <http:/ / www.scielo.br/scielo.php?script=sci_arttext\&pid=S2176-66812014000200006\&lng=en \&nrm=iso\&tlng=pt>. Acesso em 14 jul. 2019. 
BARBOSA, Eduardo Fernandes; MOURA, Dácio Guimarães de. Metodologias Ativas de aprendizagem na educação profissional e tecnológica. In B. Tec. Senac, Rio de Janeiro, v. 39, n.2, p.48-67, maio/ago. 2013.

BARIN, Alexandre; CANHA, Luciane Neves; MAGNAGO, Karine Faverzani; ABAIDE, Alzenira da Rosa. Seleção de fontes alternativas de geração distribuída utilizando uma análise multicriterial baseada no método AHP e na lógica fuzzy. Sba Controle \& Automação vol.21 no.5 Campinas Sept./Oct. 2010. Disponível em <http:/ / www.scielo.br/scielo.php?script=sci_arttext\&pid=S010317592010000500004\&lang=pt $>$. acesso em 28 jul. 2019.

BERBEL, Neusi Aparecida Navas. As metodologias ativas e a promoção da autonomia de estudantes. Ciências Sociais e Humanas, Londrina, v. 32, n. 1, p. 25-40, jan./jun. 2011.

BRASIL. Conselho Nacional de Educação. Resolução CNE/CEB Nº 6, de 20 de setembro de 2012, dispõe sobre as Diretrizes Curriculares Nacionais para a Educação Profissional Técnica de Nível Médio. Brasília, Diário Oficial da República Federativa do Brasil, 21 de setembro de 2012, Seção 1, p. 22.

BRUNE, L. Impactos da estratégia World Café num curso técnico em administração: motivação, participação e aprendizado em sala de aula. [s.l: s.n.], 2018. Disponível em: $<$ https:/ / search.ebscohost.com/login.aspx?direct=true\&db=ir01079a\&AN=ubdu.1073 7.2043\&lang=pt-br\&site=eds-live\&scope=site $>$. Acesso em: 14 jul. 2019.

DIESEL, Aline; ROOS MARCHESAN, Michele; MARTINS, Silvana Neumann. Metodologias Ativas de Ensino na Sala de Aula: Um Olhar de Docentes da Educação Profissional de Técnica de Nível Médio. Revista Signos, [S.l.], v. 37, n. 1, jun. 2016. ISSN 1983-0378. Disponível em:<file:/ / C:/Users/User/Downloads/10081017-1-PB.pdf> . Acesso em: 21 jul. 2019.

CAMARGO, F.; PITAGUARI, A.; DALBERTO, D. M. O Uso do Team-Based Learning como Estratégia de Avaliação Formativa no Curso de Administração da Uniamérica. [s. 1.], 2017. Disponível em: <https:/ / search.ebscohost.com/login.aspx?direct=true\& $\mathrm{db}=$ edsbas\&AN=edsbas.1D7C5E0A\&lang=pt-br\&site=eds-live\&scope=site $>$. Acesso em: 14 jul. 2019.

EIFLER, André Luis. Avaliação Do Desenvolvimento Da Metodologia De Aprendizagem Baseada Em Problemas Na Disciplina De Contabilidade No Curso De Técnico Em Administração. [s. 1.], 2019. Disponível em: <https:/ / search. ebscohost.com/login.aspx?direct=true\&db=edsbas\&AN=edsbas.52F84F99\&lang=ptbr\&site=eds-live\&scope=site $>$. Acesso em: 14 jul. 2019

FERNANDES, Maria Eugênia Seixas de Arruda Camargo. O World Café e o aprendizado pelo diálogo: limites e possibilidades de um território de sentidos no processo de formação. "Diagnóstico socioambiental na APA Embu Verde: Educação Ambiental para a sustentabilidade na bacia do Rio Cotia", Embu das Artes, SP. Universidade de São Paulo, Faculdade de Educação. Orientação: Marcos Ferreira Santos. São Paulo, 2015 - Tese de Doutorado. 
GIASSON, Carlos Menta. Metodologias ativas no ensino de matemática financeira em nível técnico profissionalizante: percepção de estudantes. [s.l: s.n.], 2018.

Disponível em: <https:/ / search.ebscohost.com/login.aspx?direct=true\&db=ir01079 a\&AN=ubdu.10737.2028\&lang=pt-br\&site=eds-live\&scope=site $>$. Acesso em: 14 jul. 2019.

GODOI, Alexandre Franco de. Metodologia ativa de aprendizagem para o ensino em administração: Relatos da experiência com a aplicação do Peer Instruction em uma instituição de ensino superior. Revista eletrônica de administração, ISSN: 1679-9127, v. 15, n.2, ed. 29, Jul-Dez 2016. Disponível em <file:/ / C:/Users/User / Downloads/1205-3455-1-PB.pdf>. Acesso em: 27 jul. 2019.

MORÁN, José. Mudando a educação com metodologias ativas. In Coleção Mídias Contemporâneas. Convergências Midiáticas, Educação e Cidadania: aproximação jovens. Vol II. PG: Foca Foto - PROEX/UEPG, 2-15, 2015.

MÖRSCHBÄCHER, J. L. Contribuições e desafios da metodologia instrução entre pares: um estudo de caso no ensino técnico. [s.l: s.n.], 2018. Disponível em: <https:/ / search.ebscohost.com/login.aspx?direct=true\&db=ir01079a\&AN=ubdu.10737.2207\&la ng=pt-br\&site=eds-live\&scope=site $>$. Acesso em: 14 jul. 2019.

RIBEIRO, Julio Wilson. et al. TIC e práticas na formação do educador-coinvestigador. In: Spanhol, Fernando José; Farias, Giovanni Ferreira de; SOUZA, Marcio Vieira de. (Orgs.). EAD, PBL e o desafio da educação em rede: metodologias ativas e outras práticas na formação do educador coinvestigador. São Paulo, Blucher, 2018.

SOUZA, Marcela Tavares, SILVA, Michelly Dias de, CARVALHO, Rachel de. Revisão Integrativa: o que é e como fazer? Einstein, 2010; 8(1 Pt 1):102-6. Disponível em $<$ http:/ / www.scielo.br/pdf/eins/v8n1/pt_1679-4508-eins-8-1-0102>, acesso em 20/07/2019.

WATTÉ, Bruno Henrique; SOUZA, Rafael Rodrigues de; FARIAS, Giovanni Ferreira de; SOUZA, Marcio Vieira de. Implantação da metodologia Team Based Learning (TBL) em uma estratégia de Blended Learning, no desenvolvimento da disciplina de Empreendedorismo. In: Spanhol, Fernando José; Farias, Giovanni Ferreira de; SOUZA, Marcio Vieira de. (Orgs.). EAD, PBL e o desafio da educação em rede: metodologias ativas e outras práticas na formação do educador coinvestigador. São Paulo, Blucher, 2018.

WOLLMANN, D. Analytic Hierachy Process suportando a avaliação por pares. [s. 1.], 2017. Disponível em: <https:/ / search.ebscohost.com/login.aspx?direct=true\&db=eds bas\&AN=edsbas.15052249\&lang=pt-br\&site=eds-live\&scope=site $>$. Acesso em: 14 jul. 2019. 